\title{
Managing Knowledge in A Building Information Modelling Context: A Case Study
}

\author{
Subashini Suresh, Suresh Renukappa, Haddy Jallow, and Ahmed Al Neyadi
}

\begin{abstract}
Technological innovations such as Building Information Modelling (BIM) offer opportunities to improve collaborative work and integration in the UK construction industry. The construction industry is one of the critical industries that operate in an information-rich environment, which relies heavily on knowledge as one of the strategic resources to ensure the tasks associated with the domain can be performed effectively and efficiently by the project team members. In order to take full advantages of both BIM and Knowledge Management (KM), there is a pressing need to integrate the two techniques for efficient construction projects delivery. However, very limited empirical research has been found in this area. Therefore, aim of this research is to investigate how UK construction organizations are managing knowledge in a BIM context. Qualitative case study approach was adopted to collect and analyze data. The results were derived from seven semi-structured interviews from a single project. This study revealed six key strategies that have been implemented for managing knowledge in a BIM context. They are: leadership support, improve access to knowledge assets, creating collaborative culture, hosting knowledge sharing events, capturing knowledge and creating information and communication technology infrastructure. The paper concludes that the UK infrastructure industry is heading in the right direction for implementing BIM however it is lacking knowledge management strategies. Therefore, managing knowledge in a BIM context is very critical. The leadership is most important critical success factor; leadership is about preparing organization with a Knowledge Management (KM) vision and values that resonate with the team, all employees, and key stakeholders. Therefore, there is an urgent need to develop and deliver bespoke training programs to address, improve and measure the effectiveness of leadership skills for implementing $\mathrm{KM}$ strategies in a BIM context.
\end{abstract}

Index Terms-Building information management, culture, managing knowledge, leadership, and implementation.

\section{INTRODUCTION}

During a 2016 mid-year review within the United Kingdom (UK), the construction industry has been reportedly falling back into recession for the first time in four years, even before the votes were cast to leave the European Union. Business confidence will continue to affect the construction industry as economist's report it's down to government spending cuts and this becoming another issue for intentions of private sector

Manuscript received February 12, 2018; revised May 25, 2018.

Subashini Suresh and Suresh Renukappa are with Faculty of Science and Engineering, University of Wolverhampton, Wolverhampton, WV1 1LY, UK (e-mail: s.subashini@wlv.ac.uk, suresh.renukappa@wlv.ac.uk).

Haddy Jallow is with M6 J16-19 Project Office, Holmes Chapel Road, Sandbach, CW11 1SE, UK (e-mail: Haddy.Jallow@kier.co.uk).

Ahmed Alneyadi is with Abu Dhabi Police GHQ, Abu Dhabi, United Arab Emerates (e-mail: eng.alneyadi@gmail.com). investments [1]. However, from January of 2017 it has been reported that the United Kingdom has appreciated a fast growth in new orders compared to the previous year. Housebuilders were the critical drivers behind the construction growth, work on infrastructure schemes also increased at a reasonably fast pace, while commercial construction only slightly increased [2].

It is hard to foresee what 2017 holds for the United Kingdom with only a small number predicting the major events that unfolded in the last year. With the surprise exit from the European Union comes uncertainty for construction industry. The Government have indicated a $£ 2.3$ billion spend to provide housing and infrastructure in high demand locations. In addition, $£ 1.1$ billion is to be spent on upgrading the transport networks including $£ 200$ million becoming available for traffic pinch points. Construction growth will remain reasonably flat for the year but certain areas such as the infrastructure sector will see more favorable success. A report from Glenigan has predicted forecasts of $29 \%$ growth in infrastructure for 2017 with North East, North West and Wales benefiting from the sizeable increase to construction growth [3].

From 2013 the UK economy has been expanding, and by 2014 spending within the infrastructure sector had achieved $£ 72$ bn. The UK economy is strong when comparing to other European countries, research has shown the UK's interest in investment in 2014 is assumed to increase from $22 \%$ to $23 \%$ by 2025 , with spending to achieve $£ 110$ bn [4]. During the parliament discussions, the main parties revealed their responsibility to develop the UK's infrastructure to provide transportation networks to achieve the social and economic development requirements [5].

Currently there is uncertainty in 2017 for construction companies, some will maintain their current levels and others will benefit and see good growth. The Government is dedicated to infrastructure and housing developments, the UK construction industries will gain when projects such as HS2 commence [3].

Errors in construction and engineering have become an innate feature of the design process. According to Love et al. [6] errors occur due to psychological and physiological limitations of humans. Indeed, human errors occur for various reasons, thus by different actions are needed to prevent or avoid different sorts of error experiences in construction projects. Love et al. [7] found out that design errors and subsequent rework that occurred on site for a specified project was attributable to inadequate knowledge of junior staff in their office. Indeed, such inadequacies may result in a lack of knowledge regarding the performance of building materials available, and in other words may inhibit their decision 
making. On the contrary, Hagan and Mays [8] expressed that regardless of the skill level, experience or training possessed, errors and omissions can be made at any time. In the same way, Reason [9] contends that it is often the best individuals whom commit mistakes with the worst consequences.

Love et al. [6] produced a list of twenty nine possible rework causes in construction projects. These can be loosely categorized as (1) scope changes; (2) erroneous design/documents; (3) Lack of quality management systems and (4) poor workmanship. Further digging into these headings, a number of factors can been seen as prominent, including (1) misinterpretation of drawings and specifications; (2) use of superseded drawings and specifications in the supply chain; (3) poor or imprecise communications; (4) lack of supply chain communication; (5) poor training and skill levels and inadequate supervision [10].

Implementing Building Information Modeling (BIM) into the construction industry will improve project delivery, financial accounting and safety, helping to avoid poor communication channels, inaccurate costs and improve project delivery.

\section{BUILDING INFORMATION MODELING}

The UK construction industry is facing increasing pressure by 2016; all major centrally procured government construction projects must use level 2 BIM. As the UK government procures around 30 per cent of the overall construction industry output, it is a substantial client to the construction industry [11]. It can be seen that many clients of construction firms both public and private are seeking to utilize BIM in advance of 2016 due to the benefits it may possibly bring to their projects.

BIM is far more than a simple transition to 3D modelling, representing a change to the way projects are undertaken and managed as the fundamental issues of the business process and workflows have changed. Indeed, BIM is a socio-technical system that requires centralized commitment from all organizations involved along with substantial organizational changes. Chiefly, it is as much about the individuals and the processes as it is about technological elements [12]. This implies that BIM will have a very deep impact on all individuals involved in constructions projects.

The primary difference between BIM technology and conventional 3D CAD is that second mentioned describes a building by independent $3 \mathrm{D}$ views such as elevations, sections and plans. Indeed, editing one of these views requires that all must be checked and updated, which is an error-prone process, causing poor documentation. As well, data in these 3D drawings are graphical entities only [13]. On the other hand, BIM carries all information related to the building, including its physical and functional characteristics and project life cycle information [13]. It contains data on the nature of an object, such as its geometry, its location in relation to other objects, the amount of objects and other parametric information about the object itself [14]. In other words, if an element is modified then and adjacent element or assembly is automatically adjusted to maintain a previous established relationship.
BIM as a process can be foreseen as a virtual process that serves as the base element for the exchange of data between parties involved in the project Jankowski et al., [15] encompassing all aspects, disciplines and systems of a facility within a single virtual model, allowing all team members to collaborate more efficiently than traditional processes [13]. This means that BIM is the shared digital representation based on open standards of interoperability [16]. As the model is being created, team members are constantly refining and adjusting their portions according to project specifications and design changes to ensure the model is as accurate as possible before the project physically beginnings [13]. After the completion of the design, models will contain complete information of the geometry and data needed for the pricing, design, prefabrication and other procedures [15]. Most importantly, the foundations of BIM are laid on two pillars, communication and collaboration.

The various subsets of BIM are described in terms of dimensions: 3D (object model), 4D (time), 5D (cost), 6D (operation), 7D (sustainability) and even 8D (Safety).Azhar et al. [13] defined this multidimensional capacity of BIM as ' $\mathrm{nD}$ ' modelling as it has the capacity to add an almost infinite number of dimensions to the Building Model. BIM is a model drenched in information, which aside from graphical data such as geometry and shape, also includes non-graphical information such as performance requirements and associated documentation, presented in a specification or manual format. In particular, written specification is not new and has been around for centuries. Yet, it is only now by combining these aspects of graphical and non-graphical information that the overall picture is depicted [17].

The benefits of BIM are clear to those who have adopted it. 59 per cent see cost efficiencies, 56 per cent see an improvement in client outcomes, 51 per cent an increase in the speed of delivery and 48 per cent an increase in profitability [17]. However, Xiao and Noble [11] in their research expressed that for the project performance in cost, time and quality, not one of their interviewees stated that it directly improved any of these elements, which, suggests in this circumstance it did not help reduce cost of poor quality. In addition, found that BIM was actually a disadvantage as the lack of collaborative working meant version control was lost, which increased rework. Furthermore, Xiao and Noble [11] found that in some projects the theory of BIM of everyone working together was not the case as some engineers and designers still worked in isolation. Dossick and Neff [18] acknowledged that research may show that BIM makes visible the connections among project members, although it does not foster closer collaboration across different organizations. This implies that even if the end model is a collaborative design, the process of getting there may be not. Therefore, it is necessary to integrate knowledge management principles with BIM to enhance effectiveness and efficiency of delivering construction projects.

\section{KNOWLEDGE MANAGEMENT}

The construction industry is one of the critical industries that operate in an information-rich environment, which relies 
heavily on knowledge as one of the strategic resources to ensure the tasks associated with the domain can be performed effectively and efficiently by the project team members [16]. Consequently, Khuzaimah and Hassan [19] pointed out it is clear that knowledge must be deliberately and consciously managed in a systematic manner to enable organizations to avoid repetition of costly mistakes, to achieve improved performance and reinvention of wheels. The process of managing knowledge in the construction industry is not a simple task and requires thorough planning and preparation. Due to the intrinsic characteristics of the construction industry that is highly fragmented and transient in nature [19], the success rate of managing project knowledge has been somewhat minimal [20].

In particular, KM can be seen as a tool in order to enhance organizational performance with many academic and practitioners advocating the construction organizational benefits of KM including delivery of projects with quality, shorter design and production times, customer and staff satisfaction and market leadership [21]. Egbu et al. [22] emphasized that $\mathrm{KM}$ is in fact the formalization of the admittance in the direction of experience, knowledge and expertise with the aim of creating new capacities, facilitate better quality performance, promote innovation, as well as improve customer worth. Kasimu, et al. [23] acknowledges when experiences, in other words knowledge and skills are properly shared at the right time then the same problems in the construction project do not necessarily need to be solved constantly.

In construction projects knowledge is scattered and the pool of knowledge could be lost if there is no proper channel for the knowledge created during the construction phase, for re-use on other projects [23]. Noordin et al. [24] stressed that failure to capture the knowledge and experiences during the construction phase will result in a great loss to not only the organization, but represent unnecessary wastages of assets. Indeed, Egbu et al. [22] expressed that knowledge across a project is key, in order to transfer knowledge from a current project to future developments. In other words, allows individuals to use existing proven knowledge to solve issues as a substitute of generating new knowledge, which can take up vast amounts of time and resources [25]. Thus by, this has shown the need for the development of appropriate strategy for capturing knowledge of construction projects by using technology, techniques, concept and tools. Furthermore, Egbu et al. [22] points out that capturing knowledge will help to prevent the loss of critical knowledge due to retirement, downsizing and outsourcing and discards the experts and professionals at the expiration of the project.

Egbu et al. [22] deduces that knowledge capture encompasses three sub-processes. Firstly and foremost, the identification and location of knowledge: concern with the discovering of the natures of knowledge to be managed and the location where such knowledge is situated for learning [26]. Secondly, representation and storage of knowledge: meaning indexing, organizing and structuring knowledge into exact knowledge areas and authority in the standards [21]. Finally, validation of knowledge: to ensure the credibility of knowledge captured and proper storage, with all relevant related facts and in the right format [27].
Deshpande, et al. [28] presented a framework to classify and manage knowledge and proposed a new approach to capturing, extracting, and storing data and knowledge in BIM. To strengthen its practical application and facilitate the communication and reuse of construction knowledge, Ho, et al. [29] developed a BIM based knowledge sharing system to enable managers and engineers share and manage construction knowledge and experience in the BIM environment and obtain feedback provided by jobsite engineers for future reference. The main principles of the existing studies established that: KM can effectively extract and manage fragmented expert based knowledge and experience, and facilitate data stored in a proper structure, communicated and reused; BIM is considered as the primary data repository for shared knowledge forming a reliable basis for decision making; and the visualization capabilities of BIM could help technicians or decision makers to implement the concept of 'early risk identification and prevention' and refine the plan. In order to take full advantages of both BIM and KM, there is a pressing need to integrate the two techniques for efficient construction projects delivery. However, very limited empirical research has been found in this area. Therefore, aim of this research is to investigate how UK construction organizations are managing knowledge in a BIM context.

\section{RESEARCH METHODOLOGY}

Notably, design of research methodology is a crucial and difficult step in the research process [30]. Methodology is the overall approach to the research process, from the theoretical underpinnings to the collection and analysis of data [31]. It needs to encompass the rationale and philosophical assumptions that underlie this research, which in turn influenced the methods that are used to investigate the research aim and objectives and to collect, analyze and interpret data. It is key to have a robust methodology to be able to satisfy the aim and research questions of this investigation. Since there is no background theory in this field, a qualitative research approach was selected following the theory of [32]. The case study approach was selected, as, by definition, it is an in-depth investigation of an even or serious of related events [32]. A case study approach is appropriate to understand 'sticky' practice based problems where experiences and the context of the action are important [33]. Rowley [34] explains, case studies are a useful research approach for answering why and how questions, as when it is useful to see to understand a situation. The case study research starts with an analysis and description of the situation in one organization. Employing a case study approach is useful, as it has the capability of uncovering casual influences and interaction effects, which might not be treated as operationalized variables in a statistical study. However, a common criticism of the case study is its lack of generalizability sometime called external validity [33]. The questions necessary to fulfil this research were asked in semi-structured interviews. A total of seven professionals were interviewed in a single project. A purposive sampling technique was used in order to achieve representativeness. 


\section{KNOWLedge Management PRACTICES Within the BIM IMPLEMENTED INFRASTRUCTURE PROJECT}

During the past years, little investments has signified poor maintenance on the UK's road networks, with surfacing for example now reaching life expectancy. From the condition of the UK's road infrastructure through to the network issues relating to capacity and connectivity, the UK encounters similar issues as witnessed in different countries. With ever increasing demand on the roads, capacity issues deem some roads not sufficient [13].

Smart motorways are developed to control traffic flow which will enhance the network. Live monitoring and control of traffic conditions enables improved capacity by applying variable mandatory speed limits. Vehicles are controlled via vehicle detection technology that feeds the information to a control system which inspects the information and categorizes it into either congestion or queueing traffic. The varying traffic conditions automatically activate the suitable signage and speed restrictions. This system also manages the hard shoulder running option, allowing the opening and closing of the hard shoulder during the detection of peak flows. There is an option for all lanes running; this permanently opens the hard shoulder as an additional running lane [13].

Smart motorways are essential for improving safety, congestion and reducing carbon. Applying these technologies and incorporating them into BIM will deliver opportunities for monitoring the condition of road surfaces. Traffic count, weather conditions, vehicle types and traffic incidents can be recorded and used for the implementation of future maintenance plans.

In this study, during semi-structured interviews, interviewees were asked to explain how knowledge is managed in a BIM context. Following section presents the findings.

\section{A. Leadership Support for KM}

Organization leadership forms the foundation for successful KM implementation [27]. Ichijo and Nonaka's [35] emphasize the role of leadership in building and managing knowledge in organizations. By reviewing the literature to provide a framework for assessing $\mathrm{KM}$ and $\mathrm{KM}$ success factors, Jennex and Olfman [36] noted that leadership is one of the most important critical success factors. For instance, one of the interviewees noted that: "The leadership team is also very helpful when it comes to expanding knowledge. Within the organization if anyone has a course that they want to attend and think that it would help them expand their knowledge all they would have to do is ask and if the course is beneficial they would book you the course to attend. Furthermore, about five months ago the leadership team decided to open four positions as a junior leader in which anyone in the office could apply for the role go through an interview and once you get through you would get the opportunity to shadow a leader of your choice and they would teach you and share how the leadership position goes".

The aforementioned statement suggests that construction organizations are creating a new leadership positions at the organization or project levels to create culture for knowledge capture and sharing. An effective knowledge map can change the culture and behavior of an organization, if management supports and demonstrates that change. Creating and maintaining the knowledge maps is a leadership responsibility that can be supported by good KM practices and often the introduction of $\mathrm{KM}$ technologies. If it becomes clear that people just do not know what the skills and expertise of others are, an organization may accelerate its adoption of technologies to support expertise location, communities of practices, virtual meetings, instant messaging, and so on. Face-to-face or other real-time programs that bring people together to share their individual experience and expertise start to break down the "don't know" barriers.

Leadership commitment to KM initiatives would assist in breaking down barriers in achieving KM goals- barriers such as tunnel vision, past practice, old ideas and cultural frameworks that together combine to discourage new visions of the future. Therefore, leadership is crucial for managing knowledge in a BIM context. Leadership skills need to be reinforced by the corporate values, the funding of corporate change programs and willingness to transform organizations towards knowledge based view of the firm.

\section{B. Improve Access to Key Knowledge Assets}

The sharing of best practices and lessons learnt in BIM environments is essential to any given project. Lack of knowledge sharing within BIM projects often lead to delays, costs exceeding the agreed budget and poor quality. Therefore the key driver for managing knowledge is to improve access of key knowledge assets related to BIM. This develops a vast improvement to BIM area uniting the different disciplines, sharing BIM construction procedures and available resources. Utilizing BIM knowledge on a project will enhance the communication chain throughout the lifecycle of a project, developing information and knowledge which is extremely beneficial to the success of delivering a project on-time and within budget. BIM provides a consistent platform for disciplines to manage and share their knowledge and information. The knowledge generated throughout the lifecycle of a project is one of the most important assets for any organization. Reuse of this knowledge is critical for the successful execution of infrastructure programs and thus vital for competitiveness and survival of the organizations.

\section{Creating Collaborative Culture for Managing Knowledge}

Duarte and Snyder [37] identified culture as "a set of morals, values, attitudes, beliefs and meanings that are shared by the members of a group or organization". Culture is often the primary way in which one 'group', organization, or team differentiates itself from others.

Silo syndrome is where managers work in the narrow confines of their departmental walls, see their colleagues as competitors and hoard valuable knowledge. In most cases the "silo syndrome" is a symptom of management failure in an environment that promotes silo behavior. In the current study, one of the interviewees noted that: "In some projects, each team just work on their own and stick to what they are doing, however within our project, having all teams in one office, i.e. the designers, subcontractors, client representative and us, the main contractors, ideas are shared between all teams, the designers get concerns from us and if we had a better idea 
about the design it is considered by them and in some cases our idea would be utilized for the design".

Other interviewees noted that: "We use the model to share concerns to the other disciplines, from viewing the design in $3 \mathrm{D}$ and visualizing how all aspects of the project interact, we can raise concerns to the different teams highlighting and concerns we have and raise discussions that can solve the concerns which effectively saves us time and money as they issue was highlighted prior to the works commencing".

The aforementioned view of the interviewee highlighted that the "silo" mentality is counterproductive to KM initiatives. A pervasive silo mentality can lead to a "moribund" organization, an organization that is dying a slow death. Many experienced construction professionals see knowledge as power and are reluctant to share it. The major reason behind this was that knowledge is seen as power. The perception is that holding onto individual knowledge makes a person more valuable to the organization, while capturing that knowledge makes a person vulnerable and almost expendable. This is supported by Davenport [38] who claims that some managers see knowledge capture as threatening and 'unnatural'. As noted by the interviewees in this study, the establishment of a network throughout the organization (each with its own internal and external networks and contacts) provides a base of knowledge and support that individual employees could draw upon to help them diffuse ideas and expertise within their own context of work.

\section{Hosting Knowledge Sharing Events}

Brown and Duguid [39] suggested that training is more than the transmission of abstract knowledge. Knowledge can be constructed in interactions with the social and physical world. Training experiences or events may, therefore, need to be developed in a way to nurture both knowledge capture and also construct new knowledge in a given context.

In the current study, one of the interviewees noted that: "Within our project we conduct a 'lunch and learn' event every Wednesday for about 30 minutes. This involves a volunteer to produce a short presentation on what they are currently working on or a new theory they have come across. The staffs then attend the 'lunch and learn' event during lunch times where we have lunch and see a presentation from a member of staff. The onsite teams which are on site during the 'lunch and learn' times usually have knowledge shared first thing in the morning before they head off to site. An induction is held every Tuesday, Wednesday and Thursday at 7 am first talking about health and safety on site and then following on from that a specific topic is chosen and a volunteer from either the office staff or on site team can present this".

Other interviewees noted that: "In our project, as it is a joint venture, there are BIM people in both companies. With my manager being from our partner company, he has been helpful in introducing the whole team to the BIM group at the company, there are Digital Construction Day forums which happen every three months which we attend and share ideas. The digital construction day forum is our partner company event and all their BIM managers from all projects around the UK meet at the head office and discuss about what they are doing at their project and share ideas".

The aforementioned view of the interviewee highlighted that by encouraging formal and informal strategies there is a continual capture and exchange of knowledge which leads to the generation of new knowledge and ideas for project innovations. It is recommended, that organizations invest in training about the benefits of managing knowledge in their work practices. However, training in non-working hours can be difficult if employees have other demands on their time.

\section{E. Capturing Knowledge}

Capturing tacit knowledge is the process through which experience and expertise of an individual in an organization is collected and made available to anyone who needs it [40]. One of the interviewees in the current study noted that: "The environment within our organization is an extremely friendly one. Being a graduate engineer and learning the theoretical portion of engineering, being in the office and experiencing the practical side can be quite tricky and being young it might be a struggle to find your feet, however with the both office staff and workforce being friendly everyone within the project is open for questions. Knowledge in the office is not kept under wraps, with all teams being extremely helpful and willing to share it is just a matter of asking. Working with the Building Information Model, it requires gathering information on all aspects of the project, for example structures. The production of the structures as-built models involves collecting as-built information from the structures team, some of the structures are to undergo encapsulation on the piers and others have cathodic protection. Coming straight from university, cathodic protect was a new concept and sitting down with one of the section managers for 30 minutes, this was explained to me as I was to model the cathodic protection and in order to do so I needed to understand what it was, once understood it was clear to me how to model the cathodic protection and what it's purpose was for the structure".

The aforementioned view of the interviewee highlighted that capturing key lessons learned by others as well as good work practices helps to prevent firms from repeating errors while allowing new project teams to build on the work of their predecessors. Without doubt capturing knowledge may be difficult, particularly in the case of tacit knowledge. Knowledge often remains tacit until someone asks an appropriate question. At that point tacit knowledge can become explicit, but unless that knowledge is captured for someone else to use it again at a later date, learning, productivity and innovation are stifled. Knowledge work already represents $40 \%$ of the global economy. Unfortunately, over $50 \%$ of organizational knowledge is tacit and non-formalized. It is resident in the minds of its workers. Hence, the capture of knowledge is vital for any organization, especially key decisions, made based on experience which is usually shared informally.

\section{F. Creating Information and Communication Technology Infrastructure}

In today's knowledge economy, rapid access to knowledge is critical to the success of many organizations. Therefore, appropriate technology is likely to be the one of the most important factor in leveraging knowledge in organizations. For instance, one of the interviewees noted that: "Within our 
company, we have an online forum where ideas can be shared and questions can be asked if people are having problems that they haven't come across, which anyone who has come across them can help by replying to the comment. The main way we share best practices is through these forums that we go on. Both organizations share their ideas as all BIM people attend both organizations forums and when there is an idea that can benefit one another is it trialed. There is no shortage of people to ask for help from. For example with our data base being BIM Xtra from clearbox if any of the team mates are stuck there is a support link on the website where a ticket can be raised asking any question and as the clearbox team are about a team of four people they are quite friendly and outgoing. When it comes to the modelling side we have CAD technicians who work with us and have been in the industry for over 20 years. With their expertise they help with any questions raised".

The aforementioned statement suggests that technology such as online forums are well suited to provide support to the development of effective communication, both within and between communities. The technological potential to support collaboration may be available, but problematic socio-technical issues with respect to intra-community knowledge sharing have to be addressed. The idea of 'workplace portals' with an effective mix of structured and unstructured access to knowledge can help the process a great deal. The explanation also alludes to the fact that while KM technology is giving companies more sophisticated and easier ways to break barriers, knowledge sharing still depends on people. Information and communication technologies must work with, and not against, the key fundamentals that make human beings knowledgeable in social contexts [41]. This emphasizes the need for the transformation from tacit to explicit knowledge. Some of the advantages of ICTs are that they can lead to effective and efficient practices through the use and exploitation of knowledge and reduction in the number of mistakes being made.

\section{CONCLUSIONS}

BIM has been recognized, globally, as a technology driven process producing a digital representation of construction projects that has revolutionized the way construction projects are designed, delivered and managed. BIM adoption has been significantly increased in recent years after mandatory BIM requirements imposed by the governments and large clients in different countries. However, lack of knowledge hindering adoption of BIM strategies. In construction projects knowledge is scattered and the pool of knowledge could be lost if there is no proper channel for the knowledge created during the construction phase, for re-use on other projects. KM can effectively extract and manage fragmented expert based knowledge and experience, and facilitate data stored in a proper structure, communicated and reused. In order to take full advantages of both BIM and KM, there is a pressing need to integrate the two techniques for efficient construction projects delivery. This study revealed six key strategies that have been implemented for managing knowledge in a BIM context. They are: leadership support, improve access to knowledge assets, creating collaborative culture, hosting knowledge sharing events, capturing knowledge and creating information and communication technology infrastructure. The paper concludes that the UK infrastructure industry is heading in the right direction for implementing BIM however it is lacking knowledge management strategies. Therefore, managing knowledge a BIM context is very critical. The leadership is most important critical success factor for managing knowledge in a BIM context. Leadership is about preparing organization with a $\mathrm{KM}$ vision and values that resonate with the team, all employees, and key stakeholders. Therefore, there is an urgent need to develop and deliver bespoke training programs to address, improve and measure the effectiveness of leadership skills for implementing KM strategies in a BIM context.

\section{REFERENCES}

[1] K. Allen, UK Construction Sector Slips into Recession for First Time in Four Years, UK: Construction Industry, 2016.

[2] J. Kollewe, UK Construction Industry Enjoys Fast Growth in New Order, UK: Construction Industry, 2017.

[3] A. Wilen, Forecasts into 2017, London, UK: CIC Economic \& Policy Forum, 2017.

[4] N. Broadhead, Capital Project and Infrastructure Spending: Outlook to 2025, London: PricewaterhouseCoopers, 2015.

[5] Parliament, UK infrastructure improvements: Key issues for the 2015 [Online]. Available: Parliament2015-last updatewww.parliament.uk: Parliamentary Business

[6] P. E. D. Love, R. Lopez, and D. J. Edwards, "Reviewing the past to learn in the future: Making sense of design errors and failures in construction," Structure and Infrastructure Engineering: Maintenance, Management, Life-Cycle Design and Performance, vol. 9, no.7, pp. 675-688, 2011.

[7] P. E. D. Love, R. Lopez, and M. J. Kim, "Influence of organisational and project practices on design error costs," Journal of Performance of Constructed Facilities, vol. 28, pp. 303-310, 2014.

[8] E. Hagan and G. Mays, "Human factors engineering in the US nuclear arena," Nuclear Safety, vol. 22, pp. 337-346, 1981.

[9] J. T. Reason, "Human error: Models and management," British Medical Journal, vol. 320, pp. 768-770, 2002.

[10] S. Suresh, R. Olayinka, E. Chinyio, and S. Renukappa, "Impact of knowledge management practices on construction projects," in Proc. of the Institution of Civil Engineers - Management, Procurement and Law, vol. 170, no. 1, pp. 27-43, 2017.

[11] H. Xiao and T. Noble, "BIM'S impact on the project manager," in Proc. of 30th Annual ARCOM Conference. 1-3 September. Portsmouth: Association of Researchers in Construction Management, 2014, pp 693-702.

[12] J. Martin, "In the loop," RICS Construction Journal, vol. 2, no. 7, pp. 16-17, 2012.

[13] S. Azhar, M. Khalfan, and T. Maqsood, "Building Information Modelling (BIM): Now and beyond," Australasian Journal of Construction Economics and Building, vol. 12, no. 4, pp. 15-28, 2012

[14] L. Maia, P. Meda, and J. G. Freitas, "BIM methodology, a new approach - Case study of structural elements creation, " Procedia Engineering, vol. 114, pp. 816-823, 2015.

[15] B. Jankowski, J. Prokocki, and M. Krzeminski, "Functional assessment of BIM methodology based on implementation in design and construction company," Procedia Engineering, vol. 111, pp. 351-355, 2015.

[16] C. O. Egbu and H. S. Robinson, "Construction as a knowledge-based industry," in Knowledge Management in Construction, C. J. Anumba, C. O. Egbu, and P. M. Carrillo, Eds. Oxford: Blackwell Publishing, 2005.

[17] NBS, 2015. NBS National BIM Report, Newcastle Upon Tyne: NBS.

[18] C. S. Dossick and G. Neff, "Organizational divisions in BIM-enabled commercial construction," Journal of Construction Engineering and Management, vol. 136, no. 4, pp. 459-467, 2010.

[19] K. H. M. Khuzaimah and F. Hassan, "Uncovering tacit knowledge in construction industry: Communities of practice approach," ProcediaSocial and Behavioural Sciences, vol. 50, pp. 343-349, 2012. 
[20] Y. C. Lin and L. K. Lin, "Critical success factors for knowledge management studies in construction," ISARC Proceedings, 2006.

[21] P. Carrillo and P. Chinowsky, "Exploiting knowledge management: The engineering and construction perspective," Journal of Management in Engineering, vol. 22, no. 2-10, 2006.

[22] C. O. Egbu, S. Hari, and S. H. Renukappa, "Knowledge management for sustainable competitiveness in small and medium surveying practices," Structural Survey Journal, vol. 23, no. 1, pp. 7-21, 2005.

[23] M. A. Kasimu, A. Roslan, and A. Fadhlin, "Project knowledge management in civil engineering construction firms in Nigeria," Australian Journal of Basic and Applied Sciences, vol. 7, no. 2, pp. 54-62, 2013.

[24] M. F. Noordin, L. A. Burhanuddin, and A. Kanaa, "The current state of information management in the Malaysia construction industry," Australian Journal of Basic and Applied Sciences, vol. 6, no. 6, pp. 138-145, 2012.

[25] S. D. Fernie, S. D. Green, and R. Weller, "Knowledge sharing context, confusion and controversy," International Journal of Project Management, vol. 21, no. 3, pp. 177-187, 2003.

[26] M. L. Markus, "Toward a theory of knowledge re-use: Types of knowledge re-use Situations and factors in re-use success," Journal of Management Information Systems, vol. 18, no. 1, pp. 57-93, 2001.

[27] S. Kim, E. Suh, and H. Hwang, "Building the knowledge map: An industrial case study," Journal of Knowledge Management, vol. 7, no. 2, pp. 34-45, 2003.

[28] A. Deshpande, S. Azhar, and S. Amireddy, A framework to leverage BIM for knowledge management in AEC projects. [Online]. Available: http://www.creative-construction-conference.com/wp-content/uploads /2015/01/CCC2014_A_Deshpande.pdf

[29] S. Ho, H. Tserng, and S. Jan, "Enhancing knowledge sharing management using BIM technology in construction," The Scientific World Journal, pp. 1-10, 2013.

[30] A. Akintoye, S. Renukappa, and H. Lal, "Developments in the United Kingdom Dispute resolution process," Journal of Legal Affairs and Dispute Resolution in Engineering and Construction, Special Issue: Practices and Resolution of Progress Payment Claims, vol. 7, no. 1, pp. A4514004-A4514008, 2015.

[31] J. Collis and R. Hussey, "Business research: A practical guide for undergraduate and postgraduate students," Palgrave Macmillan, Basingstoke, 2003.

[32] J. W. Creswell and C. N. Poth, Qualitative Inquiry and Research Design: Choosing among Five Approaches, Sage Publications, 2017.

[33] R. K. Yin, Doing case study research, Sage publishing, Thousand Oaks, CA, 2009.

[34] J. Rowley, "Using case studies in research," Management Research News, vol. 25, no. 1, pp. 16-27, 2002.

[35] K. Ichijo and I. Nonaka, Knowledge Creation and Management: New Challenges for Managers, New York: Oxford University Press, 2007.

[36] M. E. Jennex and L. Olfman, "Assessing knowledge management success," International Journal of Knowledge Management, vol. 1, no. 2, pp. 33-49, 2005.

[37] D. L. Duarte and N. T. Snyder, Mastering Virtual Teams, Jossey-Bass, 2001.

[38] T. H. Davenport, Information Ecology, Oxford, UK: Oxford University Press, 1997.

[39] J. S. Brown and P. Duguid, "Organizational learning and communities-of-practice: Toward a unified view of working, learning, and innovation," Organization Science, vol. 2, no.1, pp.40-57, 1991,

[40] K. Dalkir, Knowledge Management in Theory and Practice, Boston: Elsevier, 2005.

[41] P. Massingham, "An evaluation of knowledge management tools: Part 1 Managing knowledge resources," Journal of Knowledge Management, vol. 18, no. 6, pp. 1075-1100, 2014.

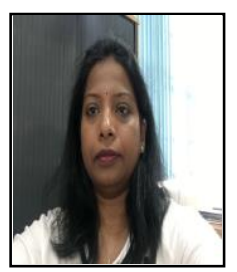

Subashini Suresh has over 19 years of experience in research, teaching and practice in the area of project management and has worked in the area of architecture, engineering and construction (AEC) sector in UK, USA, UAE, Nigeria, Ghana, Italy, Netherlands and India. Currently, she is a reader of construction project management at the School of Architecture and Built Environment, University of Wolverhampton. She holds a Ph.D in knowledge management. She received rewarding excellence award for innovation in teaching and also for blended learning tutor. She has published over 150 academic publications, which include 27 journal papers, 95 conference papers, four articles, eight book chapters, 15 reports and three books. Her key areas of interest are as follows: construction project management, knowledge management, building information modelling, health and safety, sustainability/green construction, emerging technologies, quality management, leadership in change management initiatives, organisational competitiveness, business process improvement, lean construction, risk management, and Six Sigma leadership.

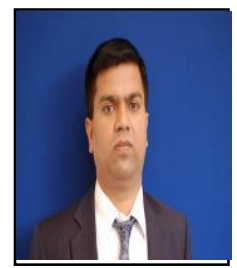

Suresh Renukappa currently serves as a senior lecturer in the Faculty of Science and Engineering at the University of Wolverhampton. He holds a Ph.D in managing change and knowledge associated with sustainability initiatives for improved competitiveness. He has over 20 years of research, consultancy, project management and teaching experience in a wide range of business and management areas across industrial sectors in both developed and emerging economies. His research interests cover, but not limited to, sustainability strategies for competitive advantage; carbon reduction strategies; corporate social responsibility; smart cities development; leading change towards sustainability; knowledge management; public private partnerships; cloud computing; infrastructure asset management; and sustainable infrastructure investment and development. He has successfully executed more than 30 large projects and authored over 80 papers which have been published in journals, book chapters and conference proceedings.

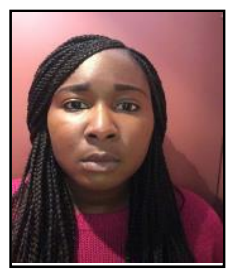

Haddy Jallow is a Building Information Modelling (BIM) co-ordinator for M20/M23 Smart Motorway Projects (SMP) with Kier, Aylesford, Kent, U.K. She holds BEng (Hons) in civil engineering from University of Wolverhampton, UK. Her research interests include BIM, project management, sustainability and knowledge management in the context of infrastructure sector.

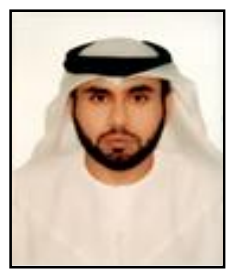

Ahmed Al Neyadi is a head of a design section in the design and operation department of the general engineering department Abudhabi Police GHQ, UAE. He holds bachelor in architectural engineering from United Arab Emirates University and a master degree in construction project management from the University of Wolverhampton, UK. In addition, he holds master of business administration in general management from the Canadian University, Dubai. Currently Ahmed is a $\mathrm{Ph} . \mathrm{D}$ researcher at the University of Wolverhampton. His research interests include sustainability strategies, low carbon infrastructure, Building Information Modelling, lean strategies and knowledge management. 